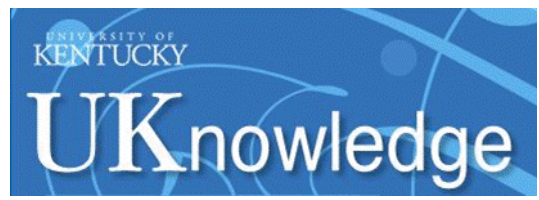

University of Kentucky

UKnowledge

Sanders-Brown Center on Aging Faculty

Publications

Aging

6-2017

\title{
Down Syndrome: Age-Dependence of PiB Binding in Postmortem Frontal Cortex Across the Lifespan
}

\author{
Harry LeVine III \\ University of Kentucky, harry.levine@uky.edu \\ H. Peter Spielmann \\ University of Kentucky, hps@uky.edu \\ Sergey V. Matveev \\ University of Kentucky, sergey.matveev@uky.edu \\ Francesca Macchiavello Cauvi \\ University of Kentucky \\ M. Paul Murphy \\ University of Kentucky, mpmurp3@email.uky.edu
}

See next page for additional authors

Follow this and additional works at: https://uknowledge.uky.edu/sbcoa_facpub

Part of the Neuroscience and Neurobiology Commons

Right click to open a feedback form in a new tab to let us know how this document benefits you.

\section{Repository Citation}

LeVine, Harry III; Spielmann, H. Peter; Matveev, Sergey V.; Cauvi, Francesca Macchiavello; Murphy, M. Paul; Beckett, Tina L.; McCarty, Katie; Lott, Ira T.; Doran, Eric; Schmitt, Frederick A.; and Head, Elizabeth, "Down Syndrome: Age-Dependence of PiB Binding in Postmortem Frontal Cortex Across the Lifespan" (2017). Sanders-Brown Center on Aging Faculty Publications. 123.

https://uknowledge.uky.edu/sbcoa_facpub/123

This Article is brought to you for free and open access by the Aging at UKnowledge. It has been accepted for inclusion in Sanders-Brown Center on Aging Faculty Publications by an authorized administrator of UKnowledge. For more information, please contact UKnowledge@lsv.uky.edu. 


\section{Down Syndrome: Age-Dependence of PiB Binding in Postmortem Frontal Cortex Across the Lifespan}

Digital Object Identifier (DOI)

https://doi.org/10.1016/j.neurobiolaging.2017.03.005

Notes/Citation Information

Published in Neurobiology of Aging, v. 54, p. 163-169.

(C) 2017 Elsevier Inc. All rights reserved.

This manuscript version is made available under the CC-BY-NC-ND 4.0 license

https://creativecommons.org/licenses/by-nc-nd/4.0/.

The document available for download is the author's post-peer-review final draft of the article.

Authors

Harry LeVine III, H. Peter Spielmann, Sergey V. Matveev, Francesca Macchiavello Cauvi, M. Paul Murphy, Tina L. Beckett, Katie McCarty, Ira T. Lott, Eric Doran, Frederick A. Schmitt, and Elizabeth Head 


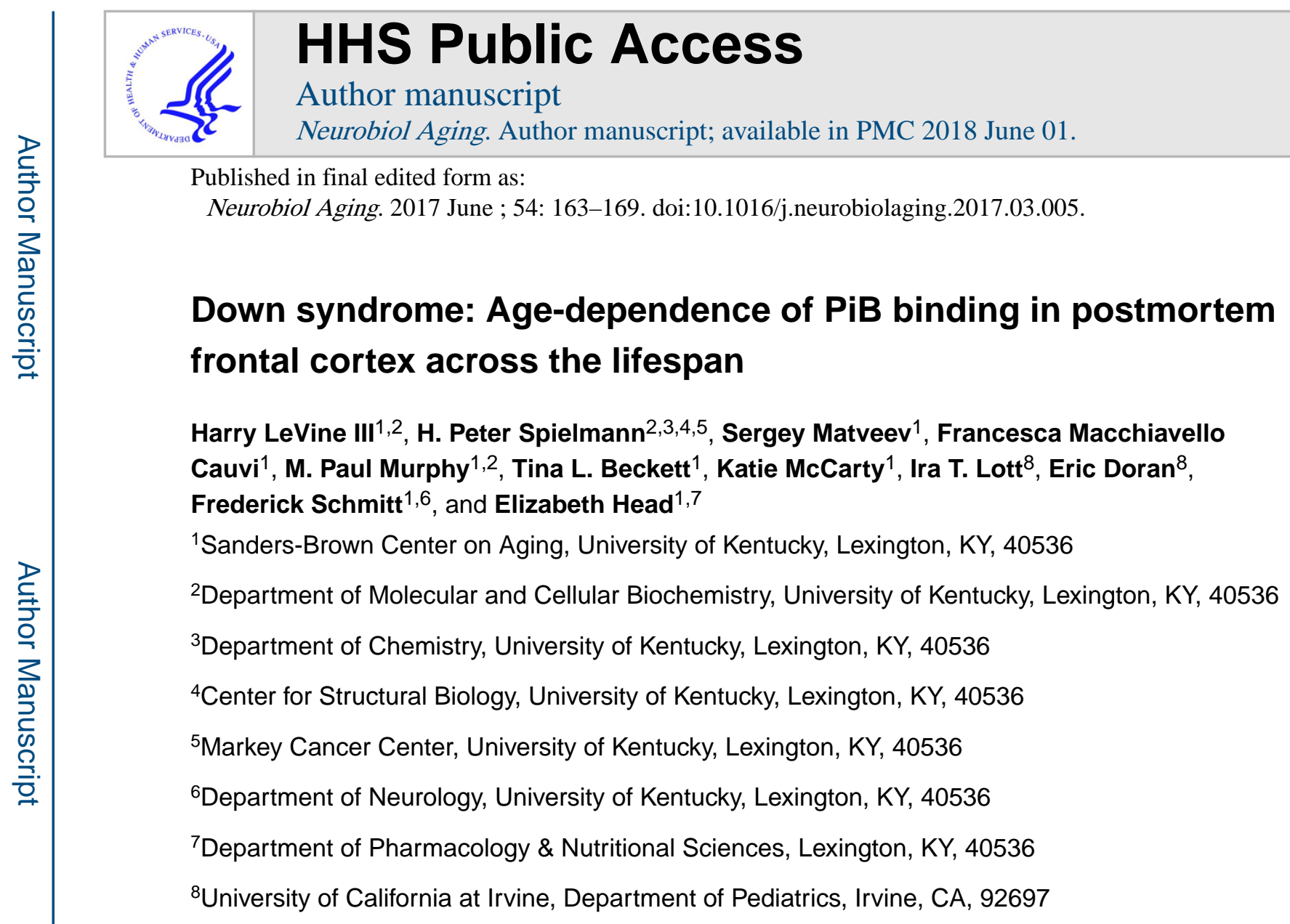

\section{Abstract}

Beta-amyloid $(A \beta)$ deposition in brain accumulates as a function of age in people with Down syndrome (DS) with subsequent development into Alzheimer disease neuropathology, typically by 40 years of age. In vivo imaging using the Pittsburgh Compound B (PiB) ligand has facilitated studies linking $\mathrm{A} \beta$, cognition, and dementia in DS. However, there are no studies of PiB binding across the lifespan in DS. The current study describes in vitro ${ }^{3} \mathrm{H}-\mathrm{PiB}$ binding in the frontal cortex of autopsy cases with DS compared to non-DS controls. Tissue from 64 cases included controls $(\mathrm{N}=25)$ and $\mathrm{DS}(\mathrm{N}=39)$. In DS, ${ }^{3} \mathrm{H}-\mathrm{PiB}$ binding was significantly associated with age. After age 40 years in DS, ${ }^{3} \mathrm{H}-\mathrm{PiB}$ binding rose dramatically along with increasing individual variability. ${ }^{3} \mathrm{H}-\mathrm{PiB}$ binding correlated with the amount of $\mathrm{A} \beta 42$. Using fixed frontal tissue and fluorescent 6-CN-PiB, neuritic and cored plaques along with extensive cerebral amyloid angiopathy (CAA) showed 6$\mathrm{CN}-\mathrm{PiB}$ binding. These results suggest that cortical $\mathrm{PiB}$ binding as shown by positron emission tomography imaging reflects plaques and CAA in DS brain.

\section{Keywords}

Aging; Alzheimer disease; Beta-amyloid; Plaques; Neurofibrillary tangles; Trisomy 21; Thioflavine $\mathrm{S} ;{ }^{3} \mathrm{H}-\mathrm{X}-34$

Corresponding author: Elizabeth Head, University of Kentucky, Sanders-Brown Center on Aging, 800 South Limestone Street, Lexington, KY, 40536, elizabeth.head@uky.edu. 


\section{Introduction}

Alzheimer disease (AD) is the most common cause of dementia in the elderly and affects 1 in 9 people over the age of 65 years (http://www.alz.org/facts/). There are currently no biomarkers for $\mathrm{AD}$ that can clearly distinguish people who will develop the disease from those who will not. The presence of beta-amyloid $(\mathrm{A} \beta)$ plaques and tau neurofibrillary tangles determined at autopsy are defining characteristics for a pathological diagnosis of AD. However, the development of in vivo ligands that selectively bind to $A \beta$, allows these lesions to be visualized and quantified in people using positron emission tomography (PET), significantly accelerating biomarker development (Cohen and Klunk, 2014;Johnson, et al., 2012; Mintun, et al., 2006; Sperling, et al., 2014). The first of these ligands, Pittsburgh Compound B (PiB) (Klunk, et al., 2004) has now been used in a large number of clinical studies in patients with $\mathrm{AD}$ and can detect $\mathrm{A} \beta$ plaques in early disease (Cohen and Klunk, 2014).

${ }^{3} \mathrm{H}-\mathrm{PiB}$ and 6-CN-PiB binding in vitro has been described in autopsy cases of $\mathrm{AD}$ in the general population (Bacskai, et al., 2007;Beckett, et al., 2012;Ikonomovic, et al., 2012;Ikonomovic, et al., 2008;Klunk, et al., 2007). A $\beta 40$ and A $\beta 42$ positive plaques as well as vascular $\mathrm{A} \beta$ bind $\mathrm{PiB}$ in vitro. $\mathrm{PiB}$ binding was more robust in compact or cored plaques and less so with diffuse plaques. Typically neurofibrillary tangles did not bind PiB except for possible weak binding to extracellular "ghost" tangles, which may be due to associated A $\beta$ (Ikonomovic, et al., 2008). Finally, PiB binding correlates early in disease with postmortem insoluble $A \beta$ measures and with plaque loads. In one case that was PET imaged in life with $\mathrm{PiB}$ and then came to autopsy, there was a significant overlap in the regional distribution of the in vivo plaque binding and in vitro PiB binding (Bacskai, et al., 2007).

Down syndrome (DS) or trisomy 21, is the most common genetic cause of intellectual disability and is associated with a neurologic phenotype that includes the development of AD neuropathology by the age of 40 years (Head, et al., 2016;Lott, 2012;Lott and Dierssen, 2010). Further, autopsy studies indicate that in DS there is an age-associated progression of $\mathrm{AD}$ neuropathology with initial deposits of $\mathrm{A} \beta$ and subsequent formation of neurofibrillary tangles (Head, et al., 2016;Hof, et al., 1995;Leverenz, 1998;Wisniewski, et al., 1985). Even so, the age of onset of dementia may be delayed by almost a decade (over 50 years of age) after AD neuropathology is present and a subset of people with DS appear to not develop dementia even at very old ages (Lai, 1989; Schupf, 2002).

PiB PET imaging studies in people with DS show that binding is age-dependent (Annus, et al., 2016;Handen, et al., 2012;Hartley, et al., 2014;Landt, et al., 2011;Lao, et al., 2016). Two of these studies included measures of impaired cognition and dementia status and found a positive significant correlation with PiB load (Annus, et al., 2016; Hartley, et al., 2014). Striatal PiB is the earliest site of binding with age in DS, typically observed after 35 years of age (Annus, et al., 2016;Handen, et al., 2012;Lao, et al., 2016) and is similar to reports of patients with presenilin-1 mutations (Klunk, et al., 2007;Koivunen, et al., 2008;Villemagne, et al., 2009). Subsequently, with increasing age, more brain regions become affected including the neocortex (Annus, et al., 2016). 
The age-dependency of PiB binding in DS in vivo may be a biomarker for $\mathrm{AD}$ neuropathology that can be used as an outcome measure in clinical trials. We hypothesized that ${ }^{3} \mathrm{H}-\mathrm{PiB}$ binding would increase as a function of age in DS in frontal cortex. Thus, we measured ${ }^{3} \mathrm{H}-\mathrm{PiB}$ binding biochemically in frontal cortex homogenates from autopsy cases with and without DS. We used the highly fluorescent PiB derivative, 6-CN-PiB, which has similar binding properties as PiB (Ikonomovic, et al., 2008; Mathis, et al., 2003) in fixed tissue to visualize plaques and, if present, cerebral amyloid angiopathy (CAA) to determine what types of pathology $\mathrm{PiB}$ binding represents in vivo.

\section{Materials and methods}

\subsection{Autopsy cases}

Frozen frontal cortex (Brodmann area 46) was obtained from 64 cases in total from the University of Kentucky Alzheimer Disease Center, the Alzheimer Disease Research Center at the University of California at Irvine, and the NIH NeuroBioBank. Human tissue collection and handling conformed to each University's Institutional Review Board guidelines.

Cases ranged from 1 to 66 years of age (Table 1). Control cases were selected to match for age and postmortem interval (PMI) to match the DS cases. Both males and females were included in the study, but given the challenges of matching cases, we did not match for gender. The level of premorbid intellectual disability or cognitive status was not available in most cases and thus it was not possible to use these variables in the analysis.

The PMI was different across groups, with the control cases showing an overall longer PMI $(\mathrm{t}(62)=3.0 \mathrm{p}=.004)$ relative to DS cases. Correlation co-efficients were thus adjusted for PMI when necessary.

\section{$2.2^{3} \mathrm{H}-\mathrm{PiB}$ binding}

${ }^{3} \mathrm{H}-\mathrm{PiB}$ binding was used to measure fibrillar $\mathrm{A} \beta$ and was assessed in homogenates of frontal cortex (Beckett, et al., 2012;Matveev, et al., 2014). Instead of the $10 \mu \mathrm{M}$ concentrations typically used for histological assay, which will also bind to low affinity sites, we used $1.2 \mathrm{nM} \mathrm{PiB}$, a concentration closer to the $\mathrm{K}_{\mathrm{d}}$ of the $\mathrm{PiB}$ analog CN-PiB for $\mathrm{A} \beta$ pathology and to the in vivo concentration of ${ }^{11} \mathrm{C}-\mathrm{PiB}$ used to visualize high affinity $\mathrm{PiB}$ binding in human $\mathrm{AD}$ brain. For binding studies, $20 \mu \mathrm{L}$ of a PBS homogenate containing $0.166 \mathrm{mg}$ wet weight tissue were added to each of three wells of a 96-well polypropylene plate (Costar 3365). $200 \mu \mathrm{L}$ of $1.2 \mathrm{nM}{ }^{3} \mathrm{H}-\mathrm{PiB}$ (cat. VT 278 specific radioactivity $=70.2 \mathrm{Ci} /$ mmol, Vitrax [Placentia, CA]) in PBS $+5 \% \mathrm{v} / \mathrm{v} \mathrm{EtOH}$ was added to two of the wells (total binding) and to the third well $200 \mu \mathrm{L}$ of $1.2 \mathrm{nM}{ }^{3} \mathrm{H}-\mathrm{PiB}+1 \mu \mathrm{M}$ unlabeled competitor BTA-1 (non-specific binding) was added. The plate was sealed with plastic film. Samples were incubated for 2 hours at room temperature without shaking, transferred to a 96-well Millipore Multiscreen HTS Hi Flow FB (GF/B) filter plate, and filtered on a multi-well plate vacuum manifold (Millipore Corporation, Bedford, MA). The filters were washed three times with $200 \mu \mathrm{L}$ of PBS $+5 \% \mathrm{v} / \mathrm{v} \mathrm{EtOH}$, dried, removed from the plate, and placed in scintillation vials with $2 \mathrm{~mL}$ of BudgetSolve scintillation fluid and counted for ${ }^{3} \mathrm{H}$. Specific 
binding for each sample was calculated as total binding (mean CPM of the two filters from wells containing radioactive $\mathrm{PiB}$ ) minus non-specific binding (CPM value from the well containing radioactive $\mathrm{PiB}+1 \mu \mathrm{M}$ nonradioactive $\mathrm{BTA}-1$ competitor).

\section{$2.3^{3} \mathrm{H}-\mathrm{X}-34$ binding}

${ }^{3} \mathrm{H}-\mathrm{X}-34$ binding (Matveev, et al., 2014) was used to measure a combination of fibrillar A $\beta$ and neurofibrillary tangles and was performed with $10 \mu \mathrm{l}$ of a PBS homogenate containing $0.166 \mathrm{mg}$ wet weight tissue similar to ${ }^{3} \mathrm{H}-\mathrm{PiB}$ binding, with $5 \mathrm{nM}{ }^{3} \mathrm{H}-\mathrm{X}-34,23 \mathrm{Ci} / \mathrm{mmol}$, custom titrated by Vitrax) (Matveev, et al., 2014) with $10 \mu \mathrm{M}$ Congo Red as the nonradioactive X-34 competitor.

\subsection{A $\beta$ ELISA}

To measure total soluble and insoluble $\mathrm{A} \beta 40$ and $\mathrm{A} \beta 42$ in frontal cortex, we used an ELISA. The methods for tissue extraction and $\mathrm{A} \beta$ measurements have been published previously (Beckett, et al., 2010). Briefly, frozen cortical samples were serially extracted to obtain fractions of different assembly states of $A \beta$. The tissue was homogenized in a Dounce homogenizer in ice cold phosphate buffered saline (PBS, pH 7.4) containing $1 \times$ complete protease inhibitor cocktail (PIC) (Amresco, Solon, OH), and centrifuged at 20,800 $\times \mathrm{g}$ for 30 minutes at $4{ }^{\circ} \mathrm{C}$. Following centrifugation, the supernatant was collected for subsequent measures of PBS soluble A $\beta$ and the pellets were sonicated $(10 \times 0.5 \mathrm{sec}$ pulses at $100 \mathrm{~W}$, Fisher Sonic Dismembrator) in room temperature 2\% SDS in PBS with PIC followed by centrifugation (as above, but at $14^{\circ} \mathrm{C}$ ). The supernatant was again collected to measure SDS soluble $A \beta$, and the remaining pellets were sonicated in $70 \%$ formic acid (FA) followed by centrifugation at $20,800 \times \mathrm{g}$ for 1 hour at $4^{\circ} \mathrm{C}$. The supernatant collected was used to measure insoluble $\mathrm{A} \beta$. $\mathrm{A} \beta$ was measured in these extracts using a standard, wellcharacterized two-site sandwich ELISA as described previously [47]. Briefly, an Immulon 4HBX plate (Dynex-Thermo Fisher) was coated with $0.5 \mu \mathrm{g} /$ well of antibody, incubated overnight at $4^{\circ} \mathrm{C}$, then blocked with a solution of Synblock (AbD Serotec, Raleigh, NC), as per the manufacturer's instructions. Antigen capture was performed using monoclonal antibody $\mathrm{Ab} 9$ (against Human $\mathrm{A} \beta(1-16)$ ). Antigen detection was performed using biotinylated antibodies 13.1.1. (end specific for $A \beta(x-40)$ ), and $12 F 4$ (end specific for $\mathrm{A} \beta(\mathrm{x}-42)$; Covance, Princeton, $\mathrm{NJ})$.

To measure insoluble $A \beta$, formic acid-soluble supernatant was initially neutralized by a 1:20 dilution in TP buffer ( $1 \mathrm{M}$ Tris base, $0.5 \mathrm{M} \mathrm{Na}_{2} \mathrm{HPO}_{4}$ ), followed by a further dilution as needed (1:100 to 1:400) in Antigen Capture buffer (AC) (0.02 M sodium phosphate buffer, $0.4 \mathrm{M} \mathrm{NaCl}, 2 \mathrm{mM}$ EDTA, 0.4\% Block Ace (AbD Serotec), $0.05 \% \mathrm{NaN}_{3}, 0.2 \% \mathrm{BSA}, 0.05 \%$ CHAPS, pH 7). SDS-soluble fractions were diluted (1:20) in AC buffer alone and PBS fractions were diluted 1:4 in $A C$ buffer alone. A peptide standard curve of $A \beta$ was run on the same plate for comparison, and standards and samples were run at least in duplicate; $A \beta$ values were determined by interpolation relative to the standard curve. Plates were washed 2-4 times between assay steps with standard PBS containing 0.05\% Tween-20 (2-4x) followed by PBS $(2-4 \times)$. Plates were developed with TMB reagent (Kirkegaard \& Perry Laboratories, Gaithersburg, MD), stopped with 6\% o-phosphoric acid, and read at $450 \mathrm{~nm}$ using a BioTek multiwell plate reader. 


\subsection{CN-PiB binding in vitro and comparison to AD neuropathology}

To visually characterize plaque and vascular binding of $\mathrm{PiB}$ in vitro, we used fixed tissue sections from the frontal cortex of two control cases (19 years and 51.3 years), DS (19.8 years), and DS with AD (DSAD) case (51.4 years) and the fluorescent cyano-PiB (CN-PiB). Sections were first mounted on slides and allowed to dry prior to incubation in $100 \mathrm{nM} \mathrm{CN}$ $\mathrm{PiB}$ for 1 hour at RT using a similar protocol as published previously (Ikonomovic, et al., 2008) but at a lower concentration closer to the $\mathrm{CN}-\mathrm{PiB} \mathrm{K}_{\mathrm{d}}$ to focus on high affinity imaging ligand-relevant binding. Slides were washed in PBS for $3 \times$ for 2 minutes then incubated briefly (30s) in TrueBlack ${ }^{\mathrm{TM}}$ lipofuscin autofluorescence quencher (Biotium, Hayward, CA). After three more 2-minute washes in PBS, slides were coverslipped using Everbrite ${ }^{\mathrm{TM}}$ mounting media (Biotium). Images were captured using an Olympus BX51 microscope with a Q Color 5 digital camera. A second set of sections was first incubated in CN-PiB as described above but prior to Trueblack quenching for autofluorescence, slides were incubated in 0.5\% thioflavine-S (Sigma-Aldrich, St. Louis, MO) in 50\% ethanol, differentiated in 50\% ethanol, washed, and then exposed to TrueBlack. Sections were coverslipped using Everbrite ${ }^{\mathrm{TM}}$.

\subsection{Statistical analysis}

SPSS for Windows and independent $t$-tests were used to test for PMI differences across the 2 groups (Control, DS). A stepwise linear regression was used to determine which outcome measure best predicted age in DS cases. Spearman rank correlations were used to measure the strength of association between specific ${ }^{3} \mathrm{H}-\mathrm{PiB}$ binding, ${ }^{3} \mathrm{H}-\mathrm{X}-34$ binding, and age in DS.

\section{Results}

\section{$3.1^{3} \mathrm{H}-\mathrm{PiB}$ binding}

We tested the hypothesis that specific ${ }^{3} \mathrm{H}-\mathrm{PiB}$ binding levels would vary as a function of age in DS. Fig. 1A shows a significant association between age at death in DS autopsy cases and the amount of ${ }^{3} \mathrm{H}-\mathrm{PiB}$ binding that was not linear but rather increased dramatically in cases over 40 years of age. A significant Spearman rank correlation between specific ${ }^{3} \mathrm{H}-\mathrm{PiB}$ binding and age in DS was observed $(\mathrm{r}=0.54 p<0.0005 \mathrm{n}=39)$, which remained after controlling for PMI ( $\mathrm{r}=0.35 p<0.03)$ but not in controls (selected to be pathology free). Additional individual variability may be due to the presence or severity of dementia, however these data were not available for this study.

\section{$3.2{ }^{3} \mathrm{H}-\mathrm{X}-34$ binding}

We next tested the hypothesis that the highly-fluorescent Congo Red derivative, ${ }^{3} \mathrm{H}-\mathrm{X}-34$, which binds to a site on amyloid fibrils in plaques and neurofibrillary tangles and that is distinct from the ${ }^{3} \mathrm{H}-\mathrm{PiB}$ binding site, would also vary with age in cases with DS. As with ${ }^{3} \mathrm{H}-\mathrm{PiB}$ binding, we observed a significant increase in specific ${ }^{3} \mathrm{H}-\mathrm{X}-34$ binding and age of death ( $\mathrm{r}=0.58 p<.0005 \mathrm{n}=39)$ in DS (but not controls, selected to be pathology free) (Fig.1B). However, this correlation was reduced with the inclusion of PMI when calculating a partial correlation co-efficient $(\mathrm{r}=0.29 p=0.08)$. 
Predicting ${ }^{3} \mathbf{H}-\mathrm{PiB}$ and ${ }^{3} \mathbf{H}-\mathbf{X}-\mathbf{3 4}$ binding-Two independent stepwise linear regressions were used to determine the best predictor of specific ${ }^{3} \mathrm{H}-\mathrm{PiB}$ or ${ }^{3} \mathrm{H}-\mathrm{X}-34$ binding with PBS soluble oligomers, PBS, SDS, and FA A $\beta 40$ and $A \beta 42$ levels included in the analysis. The SDS A 442 fraction, the amount of oligomers, and the FA fraction of $A \beta 42$ predicted specific ${ }^{3} \mathrm{H}-\mathrm{PiB}$ binding (Table 2). In contrast, ${ }^{3} \mathrm{H}-\mathrm{X}-34$ binding was best predicted by PBS oligomers and the two FA fractions (A $\beta \mathrm{x}-40$ and $\mathrm{A} \beta \mathrm{x}-42)$ (Table 2). ${ }^{3} \mathrm{H}-\mathrm{X}-34$ also binds to neurofibrillary tangles, which were not systematically measured in the current study. Interestingly, of all the measures that predict age in the DS autopsy series, specific ${ }^{3} \mathrm{H}-\mathrm{PiB}$ binding was the best, not oligomers or $\mathrm{A} \beta$ measures $(\mathrm{r}=0.50, \mathrm{~F}(1,38)=12.47 p=0.001)$.

\subsection{6-CN-PiB labeling in frontal cortex of DS and control cases}

6-CN-PiB binding was not present at detectable levels in control cases (Fig. 2A and B) and in a young case with DS (Fig.2C). The DSAD case showed significant amounts of 6-CN-PiB labeling of plaques (Fig. 2D). In addition, substantial 6-CN-PiB binding to the vasculature was observed in DSAD, consistent with CAA. Double label studies with thioflavine S clearly show that 6-CN-PiB does not bind to neurofibrillary tangles in DSAD brain (Fig. $3 \mathrm{~A})$. Thioflavine $\mathrm{S}$ binds to the same site as Congo Red and ${ }^{3} \mathrm{H}-\mathrm{X}-34$ and does not disturb 6$\mathrm{CN}-\mathrm{PiB}$ binding. At higher magnification, 6-CN-PiB appears to bind to neuritic plaques (Fig.3B). Further, 6-CN-PiB binds to the cores of plaques as thick fibrils with a halo of thioflavine S-positive amyloid fibers on the periphery (Fig. 3C).

\section{Discussion}

The current study describes age-associated high affinity specific ${ }^{3} \mathrm{H}-\mathrm{PiB}$ and ${ }^{3} \mathrm{H}-\mathrm{X}-34$ binding in autopsy cases with DS, which expands existing PiB PET studies in vivo in people with DS to now include a broad range of ages from 1 to 66 years. Instead of the $10 \mu \mathrm{M}$ concentrations of ligand used for histology, which will also bind to low affinity sites, we use $100 \mathrm{nM} \mathrm{CN}-\mathrm{PiB}$, a concentration closer to the $\mathrm{K}_{\mathrm{d}}$ of $\mathrm{CN}-\mathrm{PiB}$ for $\mathrm{A} \beta$ pathology and to the in vivo concentration of ${ }^{11} \mathrm{C}$-PiB used to visualize high affinity $\mathrm{CN}$-PiB binding in human $\mathrm{AD}$ brain. In DS, ${ }^{3} \mathrm{H}-\mathrm{PiB}$ binding increases rapidly after 40 years of age with variability between individuals also increasing with age. ${ }^{3} \mathrm{H}-\mathrm{PiB}$ binding in $\mathrm{DS}$ appears to be best correlated with $A \beta 42$ levels (SDS and FA soluble) rather than $A \beta 40$ peptide levels based on regression analyses. 6-CN-PiB binding in autopsy cases shows a preference for fibrillar, cored, and neuritic plaques along with CAA with no binding at these low concentrations to intracellular neurofibrillary tangles (Ikonomovic, et al., 2008).

In the first report of autopsy correlates of ${ }^{11} \mathrm{C}-\mathrm{PiB}$ binding in vivo in sporadic $\mathrm{AD}$, Bacskai and colleagues showed overlap in immunostaining for $A \beta$ and ${ }^{11} \mathrm{C}-\mathrm{PiB}$ binding in vitro, including CAA (Bacskai, et al., 2007). Several studies now report ${ }^{11} \mathrm{C}-\mathrm{PiB}$ binding in autopsy cases showing that in vitro binding to tissue sections, $\mathrm{PiB}$ binds to neuritic plaques and weakly to diffuse plaques. Strong binding is observed in CAA and in some cases labeling of extracellular tangles (Ikonomovic, et al., 2012;Ikonomovic, et al., 2008;Klunk, et al., 2007). In a study of a PET ${ }^{11} \mathrm{C}-\mathrm{PiB}$ negative patient with mild cognitive impairment at the time of the PET scan, but elevated CSF tau and reduced CSF A $\beta$, numerous diffuse A $\beta$ plaques and CAA were observed at autopsy suggesting either that there was insufficient 
fibrillar A $\beta$ to bind PiB in vivo (Cairns, et al., 2009) or that not all fibrillar forms of $A \beta$ bind to ${ }^{11} \mathrm{C}$-PiB. In a series of 6 older autopsy cases with PET ${ }^{11} \mathrm{C}-\mathrm{PiB}$ imaging, there was a positive correlation between $\mathrm{A} \beta$ plaque counts and extent of PiB binding (Driscoll, et al., 2012). Results from the current study also suggest that ${ }^{3} \mathrm{H}-\mathrm{PiB}$ binding in vitro in $\mathrm{DS}$ frontal cortex is associated with neuritic plaques and CAA with weak or no labeling of diffuse plaques in DS in the small set of cases we could examine. Thus, consistent with studies in sporadic $\mathrm{AD}$ and in non-DS autopsy cases, it may also be the case that 6-CN-PiB binds only a subset of A $\beta$ deposits but not those within diffuse deposits in DS. Autopsy studies suggest that diffuse plaques in DS appear prior to neuritic plaques (prior to 40 years of age) (Head, et al., 2016) but PET PiB studies show a later age of onset of binding than that observed at autopsy. In combination, these results may indicate that weak PiB binding precludes diffuse plaque visualization by PET imaging. However, higher concentrations of CN-PiB in vitro may allow it to bind to diffuse plaques in autopsy tissue and assessing more cases between $20-40$ years of age will be helpful in future to establish this possible outcome.

In the current study, we show a broad range in ${ }^{3} \mathrm{H}-\mathrm{PiB}$ binding in the frontal DS cortex that is strongly age-associated. In addition, by the inclusion of multiple measures of soluble and insoluble $A \beta 40$ and $A \beta 42$ as well as oligomers, regression analyses show that SDS soluble $\mathrm{A} \beta 42$ was the strongest predictor of PiB binding in DS but including the amount of oligomers and insoluble $\mathrm{A} \beta 42$ improved the prediction of $\mathrm{PiB}$ binding. Our study confirms and extends previous biochemical measures of PiB binding in autopsy tissue that suggest binding in vivo by PET imaging is associated with the presence of insoluble $\mathrm{A} \beta$ (Kadir, et al., 2011). Studies in autopsy tissue from the frontal cortex and hippocampus show significantly higher amounts of PiB binding in clinically characterized AD cases compared with age-matched clinically normal controls, although there can be some overlap (Ni, et al., 2013). Further, total $A \beta 40$ and $A \beta 42$ measured by ELISA also correlates with PiB binding in vitro in a case series of $5 \mathrm{AD}$ and 5 control brains (Ni, et al., 2013). In a large case series that included controls, preclinical $\mathrm{AD}$, and $\mathrm{AD}$ samples, $\mathrm{PiB}$ binding correlated with oligomeric A $\beta$, SDS soluble A $\beta$, and FA soluble A $\beta$ (Beckett, et al., 2012).

The age-dependency of our biochemical measures of PiB binding in frontal cortex in DS cases suggests a dramatic increase in $\mathrm{PiB}$ binding after the age of 40 years, which parallels age-associated increases in insoluble A $\beta 42$ (Cenini, et al., 2012). Previous studies of PiB imaging in people with DS have included volunteers from 25 years and older and we now provide data from autopsy samples as young as one year of age. Our in vitro binding assay data are consistent with PET ${ }^{11} \mathrm{C}$-PiB imaging studies in people with DS typically showing positive binding in cortex in participants over the age of 35 years (Annus, et al., 2016; Handen, et al., 2012;Hartley, et al., 2014;Landt, et al., 2011;Lao, et al., 2016). However, a caveat with our study is that we have a gap in DS autopsy cases when A $\beta$ typically begins to accumulate ( $25-40$ years). This can be a challenge with DS autopsy studies that are limited by the number of cases available. Further, we are not able to determine if clinical status may be a better predictor of ${ }^{3} \mathrm{H}-\mathrm{PiB}$ binding in vitro given that these data were not available on the current cases. Further, there as of yet is no consensus on how best to characterize severity of dementia in people with DS as standardized tests such as the MMSE, do not apply well in this cohort. 
Combined with the results of the current study, PiB binding in DS frontal cortex appears to reflect primarily fibrillar A $\beta 42$ as well as possibly extensive CAA, which may be exacerbated in DS (Wilcock, et al., 2016). However, it should be stressed that in vitro, ${ }^{3} \mathrm{H}$ $\mathrm{PiB}$ binding shows equivalent binding to both $A \beta 40$ and $A \beta 42$ (Klunk, et al., 2005). It may also be the case that ${ }^{3} \mathrm{H}-\mathrm{PiB}$ binding reflects that there is more $\mathrm{A} \beta 42$ than $\mathrm{A} \beta 40$ in brain. The significant individual variability we observe in DS autopsy studies particularly over 40 years of age may be due to the presence of dementia or to AD disease severity as suggested in a study of sporadic AD (Beckett, et al., 2012) or in disease duration.

We have focused on only the frontal cortex in the current study, which is a limitation given that the earliest signs of PET ${ }^{11} \mathrm{C}-\mathrm{PiB}$ binding in DS are in the striatum (Annus, et al., 2016; Handen, et al., 2012;Lao, et al., 2016). In these PET ${ }^{11} \mathrm{C}-\mathrm{PiB}$ binding studies, striatal binding occurs between $36-40$ years of age. A similar study using striatal samples would be very interesting in this cohort of at-risk individuals and may reveal an earlier age of onset of $\mathrm{PiB}$ binding in vitro; it would require more cases between $20-40$ years. Unfortunately, we do not as yet have frozen samples to make a similar comparison in this brain region. Future studies will evaluate both the binding of ${ }^{3} \mathrm{H}-\mathrm{PiB}$ in frozen samples and $\mathrm{CN}-\mathrm{PiB}$ in fixed striatal samples with similar hypotheses. We may predict that striatal ${ }^{3} \mathrm{H}-\mathrm{PiB}$ would have an earlier age of onset of increase in concentration than frontal cortex. It would also be critical to determine if $\mathrm{PiB}$ is binding only to plaques and $\mathrm{CAA}$ in the striatum or if other pathological features may be leading to enhanced binding. Ideally, cognitively characterized autopsy cases would be included in future studies and may help account for individual variability but these cases are a challenge to acquire currently.

\section{Acknowledgments}

The authors are grateful to Dr. William Klunk at the University of Pittsburgh for providing unlabeled X-34. 6-CNPiB was synthesized by Dr. Fanxing Zeng at the Emory University PET Center. Funding for the current study was from the National Institutes of Health (NIH)/National Institutes of Child Health and Development, Eunice Kennedy Shriver National Institute of Child Health and Human Development grant R01HD064993 (EH, FAS), NIH R21NS080576-01A1 (HL, HPS), BrightFocus A20140445 (HL) and NIH/National Institutes on Aging (NIA) P50AG16573, NIH/NIA R01AG21912 and NIH R01HD065160 (ITL, ED). A subset of the brain tissues used here were obtained from the NIH NeuroBioBank (https://neurobiobank.nih.gov/). We thank Ms. Paula Thomason for her careful editing of this manuscript.

\section{References}

Annus T, Wilson LR, Hong YT, Acosta-Cabronero J, Fryer TD, Cardenas-Blanco A, Smith R, Boros I, Coles JP, Aigbirhio FI, Menon DK, Zaman SH, Nestor PJ, Holland AJ. The pattern of amyloid accumulation in the brains of adults with Down syndrome. Alzheimers Dement. 2016; 12(5):53845. [PubMed: 26362596]

Bacskai BJ, Frosch MP, Freeman SH, Raymond SB, Augustinack JC, Johnson KA, Irizarry MC, Klunk WE, Mathis CA, Dekosky ST, Greenberg SM, Hyman BT, Growdon JH. Molecular imaging with Pittsburgh Compound B confirmed at autopsy: a case report. Arch Neurol. 2007; 64(3):431-4. [PubMed: 17353389]

Beckett TL, Niedowicz DM, Studzinski CM, Weidner AM, Webb RL, Holler CJ, Ahmed RR, LeVine $\mathrm{H}$ 3rd, Murphy MP. Effects of nonsteroidal anti-inflammatory drugs on amyloid-beta pathology in mouse skeletal muscle. Neurobiology of disease. 2010; 39(3):449-56. [PubMed: 20493261]

Beckett TL, Webb RL, Niedowicz DM, Holler CJ, Matveev S, Baig I, LeVine H 3rd, Keller JN, Murphy MP. Postmortem Pittsburgh Compound B (PiB) binding increases with Alzheimer's disease progression. J Alzheimers Dis. 2012; 32(1):127-38. [PubMed: 22766739] 
Cairns NJ, Ikonomovic MD, Benzinger T, Storandt M, Fagan AM, Shah AR, Reinwald LT, Carter D, Felton A, Holtzman DM, Mintun MA, Klunk WE, Morris JC. Absence of Pittsburgh compound B detection of cerebral amyloid beta in a patient with clinical, cognitive, and cerebrospinal fluid markers of Alzheimer disease: a case report. Arch Neurol. 2009; 66(12):1557-62. [PubMed: 20008664]

Cenini G, Dowling AL, Beckett TL, Barone E, Mancuso C, Murphy MP, LeVine H 3rd, Lott IT, Schmitt FA, Butterfield DA, Head E. Association between frontal cortex oxidative damage and betaamyloid as a function of age in Down syndrome. Biochim Biophys Acta. 2012; 1822(2):130-8. [PubMed: 22009041]

Cohen AD, Klunk WE. Early detection of Alzheimer's disease using PiB and FDG PET. Neurobiol Dis. 2014; 72(Pt A):117-22. [PubMed: 24825318]

Driscoll I, Troncoso JC, Rudow G, Sojkova J, Pletnikova O, Zhou Y, Kraut MA, Ferrucci L, Mathis CA, Klunk WE, O'Brien RJ, Davatzikos C, Wong DF, Resnick SM. Correspondence between in vivo (11)C-PiB-PET amyloid imaging and postmortem, region-matched assessment of plaques. Acta Neuropathol. 2012; 124(6):823-31. [PubMed: 22864813]

Handen BL, Cohen AD, Channamalappa U, Bulova P, Cannon SA, Cohen WI, Mathis CA, Price JC, Klunk WE. Imaging brain amyloid in nondemented young adults with Down syndrome using Pittsburgh compound B. Alzheimers Dement. 2012; 8(6):496-501. [PubMed: 23102120]

Hartley SL, Handen BL, Devenny DA, Hardison R, Mihaila I, Price JC, Cohen AD, Klunk WE, Mailick MR, Johnson SC, Christian BT. Cognitive functioning in relation to brain amyloid-beta in healthy adults with Down syndrome. Brain. 2014; 137(Pt 9):2556-63. [PubMed: 24993958]

Head E, Lott IT, Wilcock DM, Lemere CA. Aging in Down Syndrome and the Development of Alzheimer's Disease Neuropathology. Curr Alzheimer Res. 2016; 13(1):18-29. [PubMed: 26651341]

Hof PR, Bouras C, Perl DP, Sparks DL, Mehta N, Morrison JH. Age-related distribution of neuropathologic changes in the cerebral cortex of patients with Down's syndrome. Arch Neurol. 1995; 52:379-91. [PubMed: 7710374]

Ikonomovic MD, Abrahamson EE, Price JC, Hamilton RL, Mathis CA, Paljug WR, Debnath ML, Cohen AD, Mizukami K, DeKosky ST, Lopez OL, Klunk WE. Early AD pathology in a [C-11]PiB-negative case: a PiB-amyloid imaging, biochemical, and immunohistochemical study. Acta Neuropathol. 2012; 123(3):433-47. [PubMed: 22271153]

Ikonomovic MD, Klunk WE, Abrahamson EE, Mathis CA, Price JC, Tsopelas ND, Lopresti BJ, Ziolko S, Bi W, Paljug WR, Debnath ML, Hope CE, Isanski BA, Hamilton RL, DeKosky ST. Postmortem correlates of in vivo PiB-PET amyloid imaging in a typical case of Alzheimer's disease. Brain. 2008; 131(Pt 6):1630-45. [PubMed: 18339640]

Johnson KA, Fox NC, Sperling RA, Klunk WE. Brain imaging in Alzheimer disease. Cold Spring Harb Perspect Med. 2012; 2(4):a006213. [PubMed: 22474610]

Kadir A, Marutle A, Gonzalez D, Scholl M, Almkvist O, Mousavi M, Mustafiz T, Darreh-Shori T, Nennesmo I, Nordberg A. Positron emission tomography imaging and clinical progression in relation to molecular pathology in the first Pittsburgh Compound B positron emission tomography patient with Alzheimer's disease. Brain. 2011; 134(Pt 1):301-17. [PubMed: 21149866]

Klunk WE, Engler H, Nordberg A, Wang Y, Blomqvist G, Holt DP, Bergstrom M, Savitcheva I, Huang GF, Estrada S, Ausen B, Debnath ML, Barletta J, Price JC, Sandell J, Lopresti BJ, Wall A, Koivisto P, Antoni G, Mathis CA, Langstrom B. Imaging brain amyloid in Alzheimer's disease with Pittsburgh Compound-B. Ann Neurol. 2004; 55(3):306-19. [PubMed: 14991808]

Klunk WE, Lopresti BJ, Ikonomovic MD, Lefterov IM, Koldamova RP, Abrahamson EE, Debnath ML, Holt DP, Huang GF, Shao L, DeKosky ST, Price JC, Mathis CA. Binding of the positron emission tomography tracer Pittsburgh compound-B reflects the amount of amyloid-beta in Alzheimer's disease brain but not in transgenic mouse brain. J Neurosci. 2005; 25(46):10598-606. [PubMed: 16291932]

Klunk WE, Price JC, Mathis CA, Tsopelas ND, Lopresti BJ, Ziolko SK, Bi W, Hoge JA, Cohen AD, Ikonomovic MD, Saxton JA, Snitz BE, Pollen DA, Moonis M, Lippa CF, Swearer JM, Johnson KA, Rentz DM, Fischman AJ, Aizenstein HJ, DeKosky ST. Amyloid deposition begins in the striatum of presenilin-1 mutation carriers from two unrelated pedigrees. J Neurosci. 2007; 27(23): 6174-84. [PubMed: 17553989] 
Koivunen J, Verkkoniemi A, Aalto S, Paetau A, Ahonen JP, Viitanen M, Nagren K, Rokka J, Haaparanta M, Kalimo H, Rinne JO. PET amyloid ligand [11C]PIB uptake shows predominantly striatal increase in variant Alzheimer's disease. Brain. 2008; 131(Pt 7):1845-53. [PubMed: 18583368]

Lai F, Williams MD. A prospective study of Alzheimer Disease in Down Syndrome. Arch NeurolChicago. 1989; 46:849-53. [PubMed: 2527024]

Landt J, D'Abrera JC, Holland AJ, Aigbirhio FI, Fryer TD, Canales R, Hong YT, Menon DK, Baron JC, Zaman SH. Using positron emission tomography and Carbon 11-labeled Pittsburgh Compound B to image Brain Fibrillar beta-amyloid in adults with down syndrome: safety, acceptability, and feasibility. Arch Neurol. 2011; 68(7):890-6. [PubMed: 21403005]

Lao PJ, Betthauser TJ, Hillmer AT, Price JC, Klunk WE, Mihaila I, Higgins AT, Bulova PD, Hartley SL, Hardison R, Tumuluru RV, Murali D, Mathis CA, Cohen AD, Barnhart TE, Devenny DA, Mailick MR, Johnson SC, Handen BL, Christian BT. The effects of normal aging on amyloid-beta deposition in nondemented adults with Down syndrome as imaged by carbon 11-labeled Pittsburgh compound B. Alzheimers Dement. 2016; 12(4):380-90. [PubMed: 26079411]

Leverenz JB, Raskind MA. Early amyloid deposition in the medial temporal lobe of young Down syndrome patients: A regional quantitative analysis. Experimental Neurology. 1998; 150:296-304. [PubMed: 9527899]

Lott IT. Neurological phenotypes for Down syndrome across the life span. Prog Brain Res. 2012; 197:101-21. [PubMed: 22541290]

Lott IT, Dierssen M. Cognitive deficits and associated neurological complications in individuals with Down's syndrome. Lancet Neurol. 2010; 9(6):623-33. [PubMed: 20494326]

Mathis CA, Wang Y, Holt DP, Huang GF, Debnath ML, Klunk WE. Synthesis and evaluation of 11Clabeled 6-substituted 2-arylbenzothiazoles as amyloid imaging agents. J Med Chem. 2003; 46(13): 2740-54. [PubMed: 12801237]

Matveev SV, Kwiatkowski S, Sviripa VM, Fazio RC, Watt DS, LeVine H 3rd. Tritium-labeled (E,E)-2,5-bis ( $4^{\prime}$-hydroxy-3' -carboxystyryl)benzene as a probe for beta-amyloid fibrils. Bioorganic \& medicinal chemistry letters. 2014; 24(23):5534-6. [PubMed: 25452000]

Matveev SV, Spielmann HP, Metts BM, Chen J, Onono F, Zhu H, Scheff SW, Walker LC, LeVine H 3rd. A distinct subfraction of Abeta is responsible for the high-affinity Pittsburgh compound Bbinding site in Alzheimer's disease brain. J Neurochem. 2014; 131(3):356-68. [PubMed: 24995708]

Mintun MA, Larossa GN, Sheline YI, Dence CS, Lee SY, Mach RH, Klunk WE, Mathis CA, DeKosky ST, Morris JC. [11C]PIB in a nondemented population: potential antecedent marker of Alzheimer disease. Neurology. 2006; 67(3):446-52. [PubMed: 16894106]

Ni R, Gillberg PG, Bergfors A, Marutle A, Nordberg A. Amyloid tracers detect multiple binding sites in Alzheimer's disease brain tissue. Brain. 2013; 136(Pt 7):2217-27. [PubMed: 23757761]

Schupf N, Sergievsky GH. Genetic and host factors for dementia in Down's syndrome. British journal of psychiatry. 2002; 180:405-10. [PubMed: 11983636]

Sperling R, Mormino E, Johnson K. The evolution of preclinical Alzheimer's disease: implications for prevention trials. Neuron. 2014; 84(3):608-22. [PubMed: 25442939]

Villemagne VL, Ataka S, Mizuno T, Brooks WS, Wada Y, Kondo M, Jones G, Watanabe Y, Mulligan R, Nakagawa M, Miki T, Shimada H, O’Keefe GJ, Masters CL, Mori H, Rowe CC. High striatal amyloid beta-peptide deposition across different autosomal Alzheimer disease mutation types. Arch Neurol. 2009; 66(12):1537-44. [PubMed: 20008660]

Wilcock DM, Schmitt FA, Head E. Cerebrovascular contributions to aging and Alzheimer's disease in Down syndrome. Biochim Biophys Acta. 2016; 1862(5):909-14. [PubMed: 26593849]

Wisniewski K, Wisniewski H, Wen G. Occurrence of neuropathological changes and dementia of Alzheimer's disease in Down's syndrome. Ann Neurol. 1985; 17:278-82. [PubMed: 3158266] 

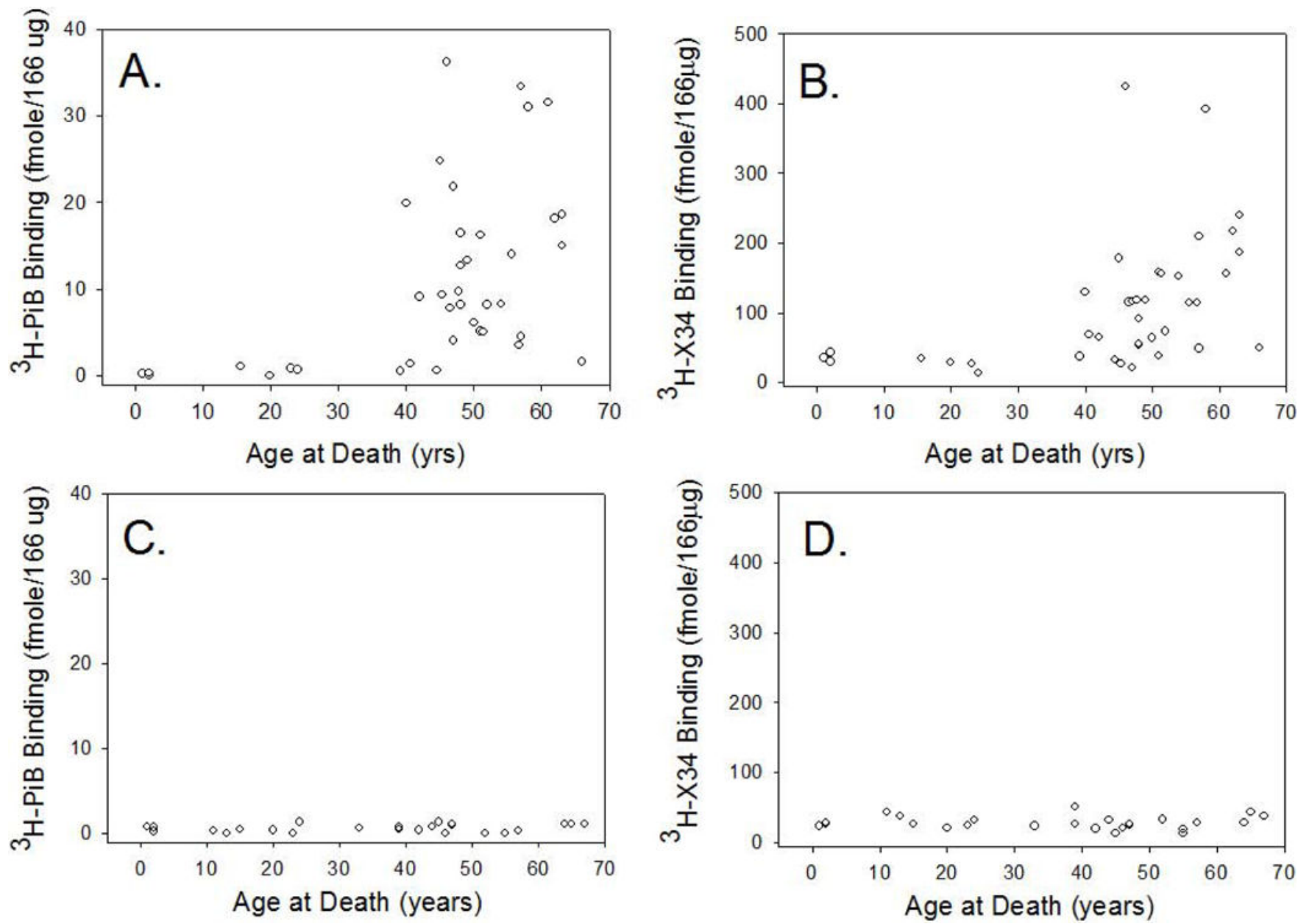

Fig. 1.

Age-Specific ${ }^{3} \mathrm{H}-\mathrm{PiB}$ and ${ }^{3} \mathrm{H}-\mathrm{X}-34$ frontal cortex binding in DS. In DS, the extent of ${ }^{3} \mathrm{H}-\mathrm{PiB}$ binding in the frontal cortex increased with age, with an exponential increase over the age of 40 years (A). ${ }^{3} \mathrm{H}-\mathrm{X}-34$ binding was also significantly increased with age (B). This is in contrast to ${ }^{3} \mathrm{H}-\mathrm{PiB}(\mathrm{C})$ and ${ }^{3} \mathrm{H}-\mathrm{X}-34$ (D) binding in similarly aged control cases showing no change as a function of age. 

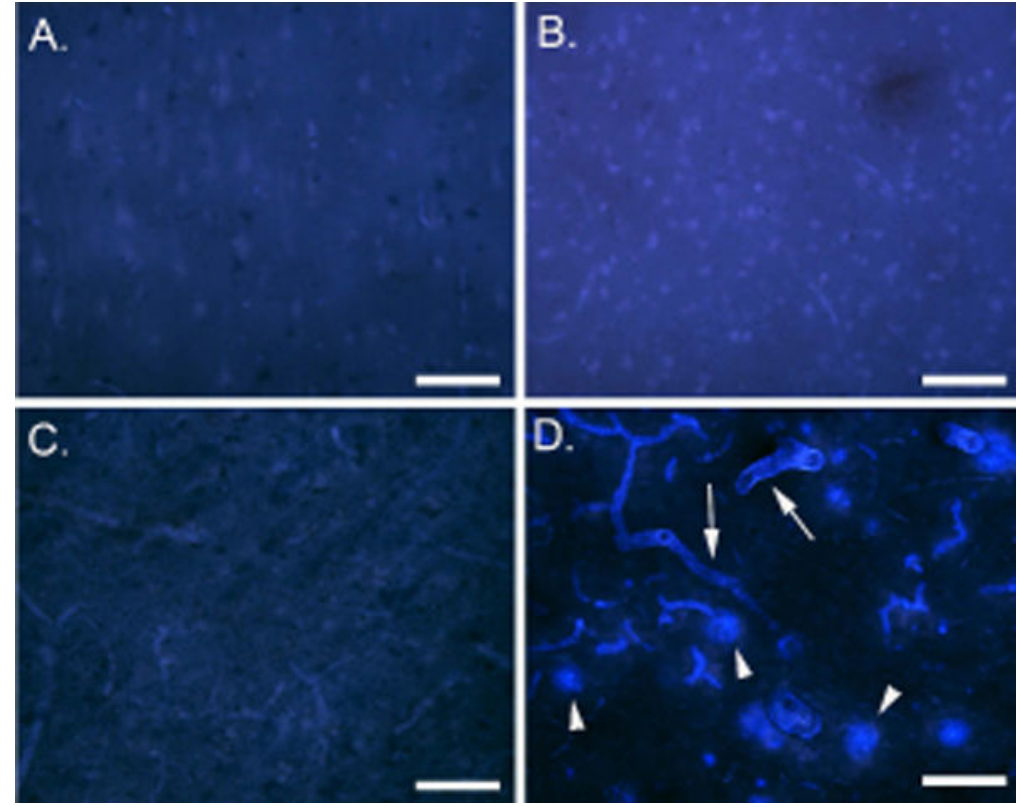

Fig. 2.

6-CN-PiB binding in the frontal cortex of DS and control cases. 6-CN-PiB binding was not observed in A. a 19-year old control case, B. a 19.8-year old DS case and, C. a 51-year old middle aged control case. In contrast, D. shows abundant 6-CN-PiB binding in plaques (arrowheads) and in CAA (arrows) in a 51.4 year old person with DS. Bar $=300 \mu \mathrm{m}$. 


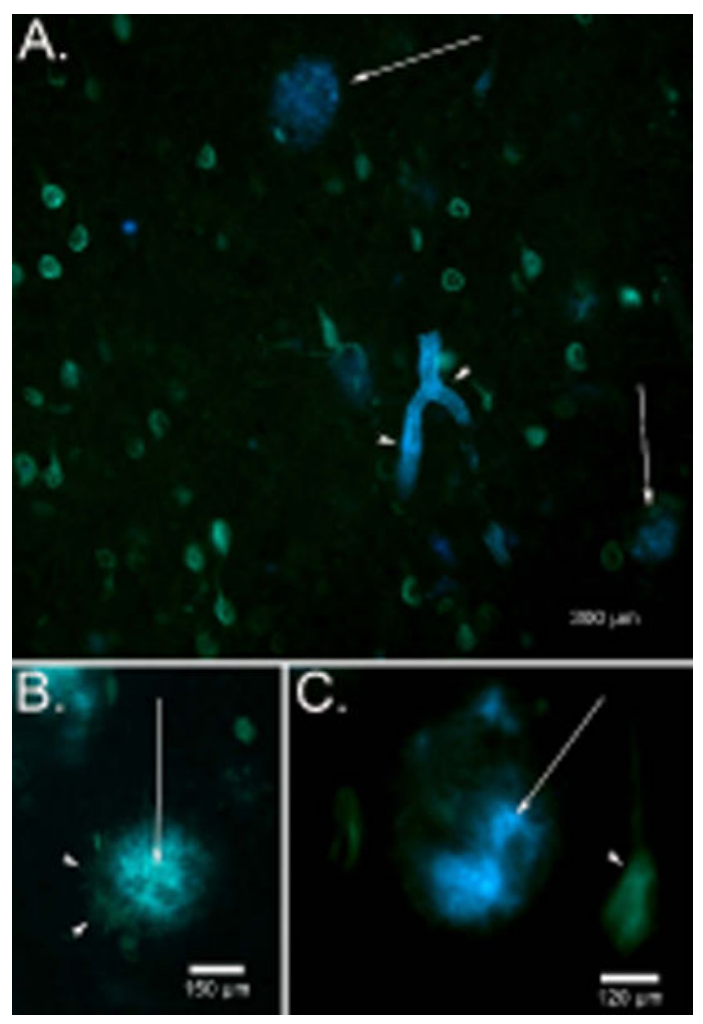

Fig. 3.

Double fluorescence labeling for 6-CN-PiB and thioflavine S in DS. (A) In a 51.4 year old DS autopsy case, 6-CN-PiB (blue) bound to plaques (arrows) and CAA (arrowheads) and could be distinguished from thioflavine $S$ labeling of neurofibrillary tangles (green). (B) A higher magnification of a single 6-CN-PiB positive plaque (arrow) shows the presence of thioflavine $\mathrm{S}$ positive dystrophic neurites (arrowheads) in the periphery suggesting a neuritic plaque. (C) In another 6-CN-PiB positive plaque (arrow), fibrils can be seen forming a positive core of the plaque, whereas thioflavine $\mathrm{S}$-positive fibrils were associated with the periphery (arrow) and were also present in neurofibrillary tangles (arrowheads). 


\section{Table 1}

Case demographics

\begin{tabular}{|c|c|c|}
\hline Characteristic & DS & Control \\
\hline N & 39 & 25 \\
\hline Mean Age (range) years & $44.1(1-66)$ & $36.4(1-66)$ \\
\hline PMI (hours) & 9.6 & 15.2 \\
\hline Female (\%) & $20(59)$ & $10(40)$ \\
\hline
\end{tabular}

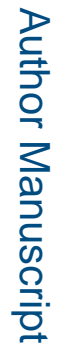

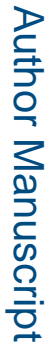

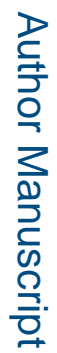

Neurobiol Aging. Author manuscript; available in PMC 2018 June 01. 
Table 2

Stepwise regression analysis of best predictors for $\mathrm{PiB}$ and ${ }^{3} \mathrm{H}-\mathrm{X}$-34binding

\begin{tabular}{|l|l|l|l|l|}
\hline Dependent & Model & R & R Square & Adjusted R Square \\
\hline \multirow{4}{*}{ Specific PiB } & SDS A $\beta 42$ & 0.711 & 0.506 & 0.499 \\
\cline { 2 - 5 } & SDS A $\beta 42+$ Oligomers & 0.788 & 0.621 & 0.610 \\
\cline { 2 - 5 } & SDS A $\beta 42+$ Oligomers + FA A $\beta 42$ & 0.811 & 0.658 & 0.643 \\
\hline \multirow{3}{*}{ Specific ${ }^{3} \mathrm{H}-\mathrm{X}-34$} & Oligomers & 0.650 & 0.423 & 0.414 \\
\cline { 2 - 5 } & Oligomers + FA A $\beta$ 40 & 0.734 & 0.539 & 0.525 \\
\cline { 2 - 5 } & Oligomers + FA A $\beta 40+F A ~ A \beta ~ 42$ & 0.760 & 0.577 & 0.558 \\
\hline
\end{tabular}

